\title{
Front Matter: Volume 9287
}

, "Front Matter: Volume 9287," Proc. SPIE 9287, 10th International Symposium on Medical Information Processing and Analysis, 928701 (29 January 2015); doi: 10.1117/12.2186892

SPIE Event: Tenth International Symposium on Medical Information Processing and SPIE. Analysis, 2014, Cartagena de Indias, Colombia 


\title{
10th International Symposium on Medical Information Processing and Analysis
}

\author{
Eduardo Romero \\ Natasha Lepore \\ Editors
}

14-16 October 2014

Cartagena de Indias, Colombia

Organized by

Universidad Nacional de Colombia (Colombia)

Sponsored by

Universidad Nacional de Colombia (Colombia)

Universidad Antonio Nariño (Colombia)

Pontificia Universidad Javeriana (Colombia)

Universidad de Cartagena (Colombia)

Published by

SPIE 
The papers included in this volume were part of the technical conference cited on the cover and title page. Papers were selected and subject to review by the editors and conference program committee. Some conference presentations may not be available for publication. The papers published in these proceedings reflect the work and thoughts of the authors and are published herein as submitted. The publisher is not responsible for the validity of the information or for any outcomes resulting from reliance thereon.

Please use the following format to cite material from this book:

Author(s), "Title of Paper," in 10th International Symposium on Medical Information Processing and Analysis, edited by Eduardo Romero, Natasha Lepore, Proceedings of SPIE Vol. 9287 (SPIE, Bellingham, WA, 2015) Article CID Number.

ISSN: 1605-7422

ISBN: 9781628413625

Published by

SPIE

P.O. Box 10, Bellingham, Washington 98227-0010 USA

Telephone +1 3606763290 (Pacific Time) · Fax +1 3606471445

SPIE.org

Copyright (C) 2015, Society of Photo-Optical Instrumentation Engineers.

Copying of material in this book for internal or personal use, or for the internal or personal use of specific clients, beyond the fair use provisions granted by the U.S. Copyright Law is authorized by SPIE subject to payment of copying fees. The Transactional Reporting Service base fee for this volume is $\$ 18.00$ per article (or portion thereof), which should be paid directly to the Copyright Clearance Center (CCC), 222 Rosewood Drive, Danvers, MA 01923. Payment may also be made electronically through CCC Online at copyright.com. Other copying for republication, resale, advertising or promotion, or any form of systematic or multiple reproduction of any material in this book is prohibited except with permission in writing from the publisher. The CCC fee code is $1605-7422 / 15 / \$ 18.00$.

Printed in the United States of America.

Publication of record for individual papers is online in the SPIE Digital Library.

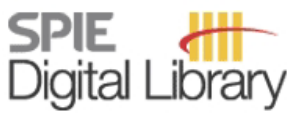

SPIEDigitalLibrary.org

Paper Numbering: Proceedings of SPIE follow an e-First publication model, with papers published first online and then in print. Papers are published as they are submitted and meet publication criteria. A unique citation identifier (CID) number is assigned to each article at the time of the first publication. Utilization of CIDs allows articles to be fully citable as soon as they are published online, and connects the same identifier to all online, print, and electronic versions of the publication. SPIE uses a six-digit CID article numbering system in which:

- The first four digits correspond to the SPIE volume number.

- The last two digits indicate publication order within the volume using a Base 36 numbering

system employing both numerals and letters. These two-number sets start with 00, 01, 02, 03, 04, $05,06,07,08,09,0 A, 0 B \ldots$. OZ, followed by 10-1Z, 20-2Z, etc.

The CID Number appears on each page of the manuscript. The complete citation is used on the first page, and an abbreviated version on subsequent pages. 


\title{
Contents
}

\author{
vii Authors \\ ix Conference Committee
}

\section{INVITED PAPER SESSION}

928703 A note on the stability and discriminability of graph-based features for classification problems in digital pathology (Invited Paper) [9287-115]

\section{MEDICAL AND BIOMEDICAL IMAGING I: BRAIN ANALYSIS}

928705 Discovering anatomical patterns with pathological meaning by clustering of visual primitives in structural brain MRI [9287-99]

928706 Morphometry-based comparison of relevant brain regions for Alzheimer's disease detection [9287-34]

928707 Multivariate analysis of eigenvalues and eigenvectors in tensor based morphometry [9287-80]

928708 Sparse Bayesian framework applied to 3D super-resolution reconstruction in fetal brain MRI [9287-86]

BIOSIGNALS I: DISEASE DETECTION

928709 Automatic detection of wheezes by evaluation of multiple acoustic feature extraction methods and C-weighted SVM [9287-71]

9287 OA Effectiveness of morphological and spectral heartbeat characterization on arrhythmia clustering for Holter recordings [9287-18]

9287 OB Extracting stationary segments from non-stationary synthetic and cardiac signals [9287-69]

\section{ANALYSIS OF MEDICAL PROCEDURES THROUGH IMAGING I: CANCER}

9287 OC A comparison of multiparametric MRI modalities to discriminate prostate cancer tumours [9287-38]

9287 OD An automatic multi-atlas prostate segmentation in MRI using a multiscale representation and a label fusion strategy [9287-52]

$9287 \mathrm{OE}$ Experimental assessment of an automatic breast density classification algorithm based on principal component analysis applied to histogram data [9287-30] 
9287 OF Segmentation of prostate from CT scans using a combined voxel random forests classification with spherical harmonics regularization [9287-58]

\section{DIGITAL PATHOLOGY}

9287 OG A comparative evaluation of supervised and unsupervised representation learning approaches for anaplastic medulloblastoma differentiation [9287-87]

$9287 \mathrm{OH}$ A statistical model for characterization of histopathology images [9287-67]

9287 ol Digital image analysis of striated skeletal muscle tissue injury during reperfusion after induced ischemia [9287-83]

9287 0J Image super-resolution of cytology images using wavelet based patch search [9287-63]

\section{MEDICAL AND BIOMEDICAL IMAGING II: HEART}

9287 OK A level set approach for left ventricle detection in CT images using shape segmentation and optical flow [9287-95]

$9287 \mathrm{OL} \quad$ A stethoscope with wavelet separation of cardiac and respiratory sounds for real time telemedicine implemented on field-programmable gate array [9287-109]

9287 OM Segment clustering methodology for unsupervised Holter recordings analysis [9287-107]

9287 ON SVM-based classification of LV wall motion in cardiac MRI with the assessment of STE [9287-78]

IMAGING OF BIOSIGNALS I: FUNCTIONAL BRAIN

928700 A T1 and DII fused 3D corpus callosum analysis in pre- vs. post-season contact sports players [9287-45]

9287 OP Dynamic functional network connectivity using distance correlation [9287-60]

$92870 Q \quad$ Influence of the segmentation on the characterization of cerebral networks of structural damage for patients with disorders of consciousness [9287-77]

9287 OR Thalamic volume as a biomarker for disorders of consciousness [9287-20]

MEDICAL AND BIOMEDICAL IMAGING III: IMAGE REGISTRATION

9287 OS An overview of alignment issues for in-vivo image guided proton therapy [9287-1 11 ]

9287 OT Non-rigid image registration under non-deterministic deformation bounds [9287-36] 
9287 OU Registration of cardiac magnetic resonance images using SURF points and matching [9287-64]

9287 OV Simultaneous registration of structural and diffusion weighed images using the full DTI information [9287-1 10]

\section{E-HEALTH AND TELEMEDICINE I}

9287 OW An open access thyroid ultrasound image database [9287-68]

9287 OX Pulse oximeter for cyclists in smartphone [9287-14]

9287 OY Towards incorporating affective computing to virtual rehabilitation; surrogating attributed attention from posture for boosting therapy adaptation [9287-26]

$92870 Z$ Towards ontology personalization to enrich social conversations on AAC systems [9287-91]

\section{E-HEALTH AND TELEMEDICINE II: SOFTWARE DEVELOPMENT}

928710 A Matlab user interface for the statistically assisted fluid registration algorithm and tensorbased morphometry [9287-500]

928711 Low-cost uncalibrated video-based tool for tridimensional reconstruction oriented to assessment of chronic wounds [9287-19]

928712 SemVisM: semantic visualizer for medical image [9287-84]

928713 TractRender: a new generalized 3D medical image visualization and output platform [9287-501]

IMAGING OF BIOSIGNALS II: SEGMENTATION

$928714 \quad$ Improved edge detection for object segmentation in ultrasound images using Active Shape Models [9287-13]

928715 Segmentation of humeral head from axial proton density weighted shoulder MR images [9287-59]

928716 Stent segmentation in IOCT-TD images using gradient combination and mathematical morphology [9287-11]

928717 Watermarked cardiac CT image segmentation using deformable models and the Hermite transform [9287-51] 
ANALYSIS OF MEDICAL PROCEDURES THROUGH IMAGING II: MOVEMENT

928718 A 3D endoscopy reconstruction as a saliency map for analysis of polyp shapes [9287-85]

928719 Automatic characterization of the Parkinson disease by classifying the ipsilateral coordination and spatiotemporal gait patterns [9287-66]

9287 1 A Characterizing the eye trajectory during the gait towards Parkinson stage identification [9287-94]

9287 1B Simulation of Parkinsonian gait by fusing trunk learned patterns and a lower limb first order model [9287-49]

BIOMEDICAL IMAGE ANALYSIS: IMAGE ENHANCEMENT

9287 1C Fast high resolution reconstruction in multi-slice and multi-view cMRI [9287-47]

9287 1D Improving the blind restoration of retinal images by means of point-spread-function estimation assessment [9287-81]

9287 IE Programmable diffractive optical elements for extending the depth of focus in ophthalmic optics [9287-92]

$9287 \mathrm{IF} \quad$ Speckle reduction in echocardiography by temporal compounding and anisotropic diffusion filtering [9287-15] 


\section{Authors}

Numbers in the index correspond to the last two digits of the six-digit citation identifier (CID) article numbering system used in Proceedings of SPIE. The first four digits reflect the volume number. Base 36 numbering is employed for the last two digits and indicates the order of articles within the volume. Numbers start with 00, 01, 02, 03, 04, 05, 06, 07, 08, 09, OA, OB...0Z, followed by 10-1Z, 20-2Z, etc.

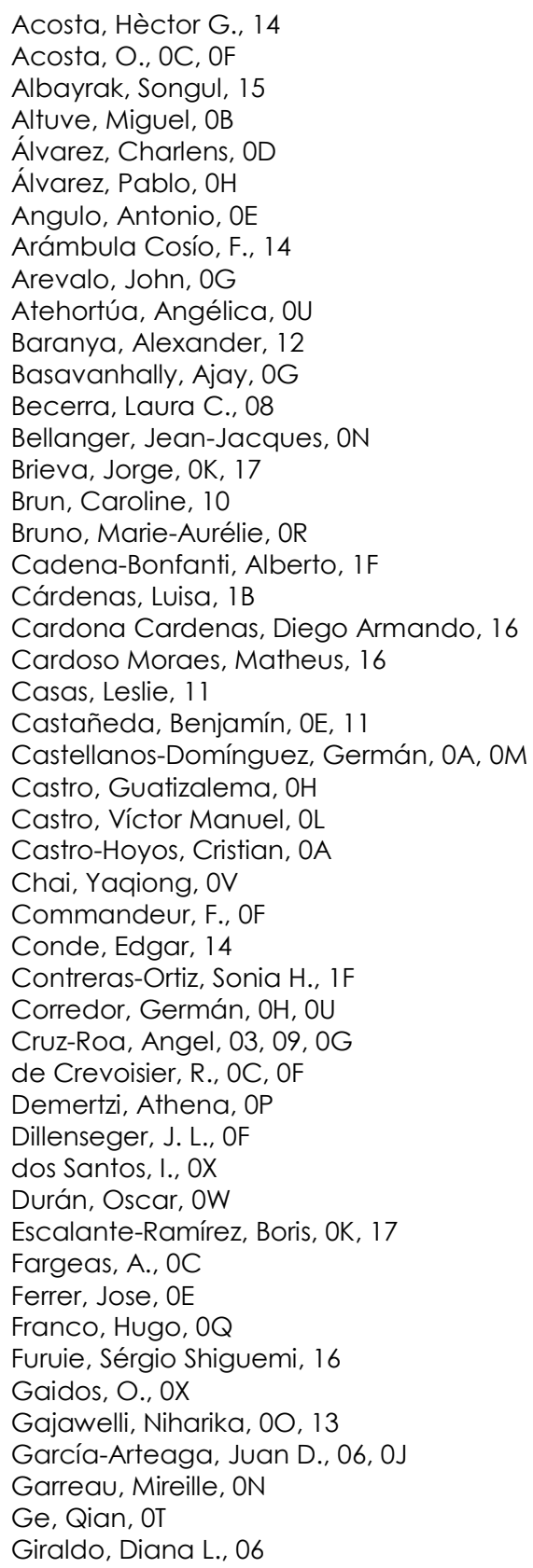

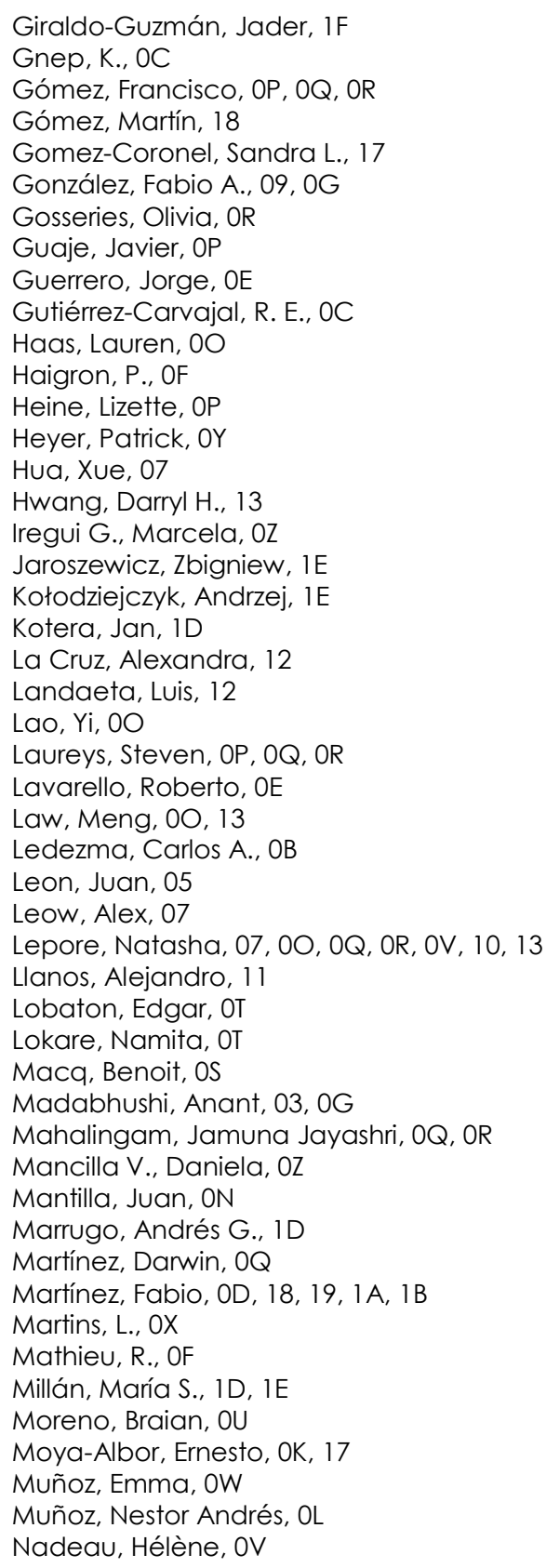


Narváez, Fabián, OW

Nelson, Marvin, OR

Orban de Xivry, Jonathan, OS

Orihuela-Espina, Felipe, OY

Ospina Arango, J. D., OF

Paredes, José Luis, ON

Pedraza, Lina, OW

Peluffo-Ordóñez, Diego Hernán, OA, OM

Perpiñán, Gilberto, OB

Pinto, Joseph, OE

Porto-Solano, Oscar, $1 \mathrm{~F}$

Pulido, Andrea, 05

Rajagopalan, Vidya, 07

Rivas, Jesús J., OY

Rodríguez, María G., OB

Rodríguez-Sotelo, José Luis, OA, OM

Rolland, Y., OC

Romero, Eduardo, 05, 06, 08, 0D, 0H, 0J,

OU, OW, 18, 19, 1A, 1B, 1C

Romero, Lenny A., $1 \mathrm{E}$

Rosero Salazar, Doris Haydee, 01

Ruano, Josue, 18

Rubeaux, Mathieu, OR

Rudas, Jorge, OP

Salazar Monsalve, Liliana, 01

Salazar, Antonio José, OL

Sant, Nishita, 10

Sarmiento, Fernanda, 19

Sastoque H., Sebastian, $\mathrm{OZ}$

Schwartzman, Armin, 07

Sezer, Aysun, 15

Sezer, Hasan Basri, 15

Shi, Jie, 00

Simon, A., OF

Soddu, Andrea, OP, OQ, OR

Šorel, Michal, 1D

Sosa, Germán D., 09

Šroubek, Filip, 1D

Sucar, Luis Enrique, OY

Thompson, Paul, 07, 0V, 10

Treuillet, Sylvie, 11

Trujillo, David, 1A

Tsao, Sinchai, 13

Tshibanda, Luaba, OP

Valencia, Braulio, 11

Vanhaudenhuyse, Audrey, OR

Vargas, Carlos, 0J, OW

Velasco Toledo, Nelson, 08, 1C

Vidal, María-Esther, 12

Wang, Yalin, 00

Wong, Sara, OB

$\mathrm{XU}, \mathrm{Jun}, 03$

Yepes-Calderon, Fernando, 10 


\title{
Conference Committee
}

\author{
Conference Chairs
}

Eduardo Romero, Universidad Nacional de Colombia (Colombia)

Natasha Lepore, Children's Hospital Los Angeles (United States) and The University of Southern California (United States)

Conference Program Committee

Juan D. García-Arteaga, Universidad Nacional de Colombia (Colombia)

Marcela Iregui, Universidad Militar Nueva Granada (Colombia)

Andrea Rueda, Pontificia Universidad Javeriana (Colombia)

Gloria Díaz, Universidad Antonio Nariño (Colombia)

Rosa Milanés, Universidad de Cartagena (Colombia)

Session Chairs

1 Medical and Biomedical Imaging I: Brain Analysis

Cristina Santa Marta, Hospital General Gregorio Marañón (Spain)

2 Biosignals I: Disease Detection

Aggelos K. Katsaggelos, Northwestern University (United States)

3 Analysis of Medical Procedures Through Imaging I: Cancer

Annant Madabushi, Case Western University (United States)

4 Digital Pathology

Fabio Gonzales, Universidad Nacional de Colombia (Colombia)

5 Medical and Biomedical Imaging II: Heart

Alfredo Hernandez, Université de Rennes 1 (France)

$6 \quad$ Imaging of Biosignals I: Functional Brain

Norberto Malpica, Universidad Rey Juan Carlos (Spain)

7 Medical and Biomedical Imaging III: Image Registration

Juan D. García-Arteaga, Universidad Nacional de Colombia

(Colombia)

$8 \quad$ E-Health and Telemedicine I

Nick Hine, University of Dundee (United Kingdom) 
9 E-Health and Telemedicine II: Software Development Ignacio Larrabide, Universidad Nacional del Centro de la Provincia de Buenos Aires (Argentina)

10 Imaging of Biosignals II: Segmentation

Maxime Descoteaux, Université de Sherbrooke (Canada)

11 Analysis of Medical Procedures Through Imaging II: Movement Oscar Acosta, Université de Rennes 1 (France)

12 Biomedical Image Analysis: Image Enhancement

Francisco Gómez, Universidad Central (Colombia)

Reviewers

Javier F. Adur, Universidad Nacional de Entre Ríos (Argentina)

Miguel Altuve, Universidad Simón Bolívar (Venezuela)

Marc Bellemare, Laboratorie des Sciences de l'Information et des Systèmes (France)

Antonio Bravo, Universidad Nacional Experimental del Táchira (Venezuela)

Jorge Brieva, Universidad Panamericana (Mexico)

Juan Carlos Caicedo, University of Illinois at Urbana-Champaign (United States)

María Victoria Carreras, Universidad Panamericana (Mexico)

Alexander Cerquera, Universidad Antonio Nariño (Colombia)

Patricia Cifuentes, Universidad Antonio Nariño (Colombia)

Boris Escalante-Ramírez, Universidad Nacional Autónoma de México (Mexico)

Jairo Espinosa, Universidad Nacional de Colombia (Colombia)

José Flórez, Universidad de Antioquia (Colombia)

Leonardo Flórez, Pontificia Universidad Javeriana (Colombia)

Crescencio García, Universidad Nacional Autónoma de Mexico (Mexico)

Francisco Gómez, Universidad Central (Colombia)

Fabio González, Universidad Nacional de Colombia (Colombia)

Ricardo Gutierrez, Université de Rennes 1 (France)

Alfredo Hernandez, Université de Rennes 1 (France)

Nidiyare Hevia, Universidad Nacional Autónoma de Mexico (Mexico)

Nick Hine, University of Dundee (United Kingdom)

Andrew Janowczyk, Indian Institute of Technology Bombay (India)

Alexandra La Cruz, Universidad Simón Bolivar (Venezuela)

Rory Lewis, University of Colorado at Colorado Springs (United States) and Anschutz Medical Campus, University of Colorado Denver (United States)

Olivier Lezoray, Université de Caen (France)

Anant Madabushi, Case Western Reserve University (United States) 
Norberto Malpica, Universidad Rey Juan Carlos (Spain)

Gabriel Mañana, Universidad Nacional de Colombia (Colombia) José Vicente Manjón, Universidad Politécnica de València (Spain)

Alfredo Mantilla, Tecnológico de Monterrey (Mexico)

Antoine Manzanera, École Nationale Supérieure de Techniques Avancées - ParisTech (France)

Ferrán Marqués, Universitat Politècnica de Catalunya (Spain)

Verónica Medina, Universidad Autónoma Metropolitana (Mexico)

Ruben Medina, Universidad de los Andes (Venezuela)

Ernesto Moya Albor, Universidad Panamericana (Mexico)

Luciana Nedel, Universidade Federal do Rio Grande do Sul (Brazil)

Quentin Noirhomme, Université de Liège (Belgium)

Carlos Ortiz de Solorzano, Universidad de Navarra (Spain)

José Luis Paredes, Universidad de los Andes (Venezuela)

Javier Pascau, Hospital General Gregorio Marañón (Spain)

Angélica Pérez-Fornos, Université de Genève (Switzerland)

Raul Ramos, Universidad Industrial de Santander (Colombia)

Oscar David Robles, Universidad Rey Juan Carlos (Spain)

Katya Rodríguez, Universidad Nacional Autónoma de México (Mexico)

Luis Eduardo Rodriguez, Escuela Colombiana de Ingeniería Julio Garavito (Colombia)

Mónica Rojas, Universitat Politècnica de Catalunya (Spain)

Antonio Salazar, Universidad de los Andes (Colombia)

Olivier Salvado, CSIRO (Australia)

Cristina Santa Marta, Hospital General Gregorio Marañón (Spain)

Daniel Suárez, Pontificia Universidad Javeriana (Colombia)

Ramiro Velazquez, Universidad Panamericana (Mexico)

Alejandro Weinstein, Universidad de Valparaíso (Chile)

María Zuluaga, University College London (United Kingdom) 
Proc. of SPIE Vol. $9287928701-12$

Downloaded From: https://www.spiedigitallibrary.org/conference-proceedings-of-spie on 26 Apr 2023 Terms of Use: https://www.spiedigitallibrary.org/terms-of-use 